Jaurnal of Environmental Science, Computer Science and Engineering \& Technology

An International Peer Review E-3 Journal of Sciences and Technology

\author{
Available online at www.jecet.org
}

Section B: Computer Science

Research Article

\title{
Finite Element Analysis of a Heavy Truck Frame Based on ANSYS Workbench
}

\author{
SUN Hongyi \\ College of Transportation and Vehicle Engineering, Shandong University of Technology, Zibo \\ 255049, China
}

Received: 04 September 2021; Revised: 26 September 2021; Accepted: 10 October 2021

\begin{abstract}
As the main bearing component of the whole vehicle, the performance of the frame is directly related to the performance of the whole vehicle. The threedimensional solid modelling of a heavy truck frame is carried out by using SolidWorks software, and its finite element model is established by ANSYS Workbench software. Then the deformation and stress distribution of the frame under bending, torsion and braking conditions are analyzed, and the strength of the frame is checked at the same time. The results show that the strength and deformation of the frame meet the design requirements, which lays a foundation for further structural optimization.
\end{abstract}

Keywords : truck frame ; finite element analysis ; ANSYS Workbenc

\section{INTRODUCTION}

In recent years, with the rapid development of China's economy and the continuous improvement of transportation infrastructure, the automobile industry has also been vigorously developed. As the bearing component of automobile, the importance of automobile frame design is self-evident.The function of the frame is to support and connect various parts of the car, and bear various loads from inside and outside the car. When the vehicle runs on rough roads, the frame may produce torsional deformation and bending deformation in the longitudinal plane under the action of load; When one wheel encounters obstacles, it may also twist the whole frame into a rhombic shape. These 
deformations will change the relative position between the components installed on the frame, thus affecting its normal operation. Therefore, the frame should have sufficient strength and appropriate stiffness ${ }^{[1]}$. Therefore, taking the frame of a heavy truck as the research object, this paper makes a static analysis of the frame under four working conditions: bending, torsion, emergency braking and turning ${ }^{[2]}$.

\section{MATERIALS AND METHOD}

2.1 Establishment of finite element model: In this paper, a heavy truck frame is taken as the research object. The frame adopts side beam design, which is composed of two longitudinal beams and six transverse beams. The overall length of the frame is $8100 \mathrm{~mm}$ and the total width is $860 \mathrm{~mm}$. There are many small parts on the frame and have little impact on the strength and stiffness of the whole frame. In order to facilitate the analysis and appropriately simplify the geometric structure of the frame, the three-dimensional assembly model of the frame is established by using SolidWorks software, as shown in Figure 1-1. Then import the model into ANSYS Workbench software through the interface to establish its finite element model.

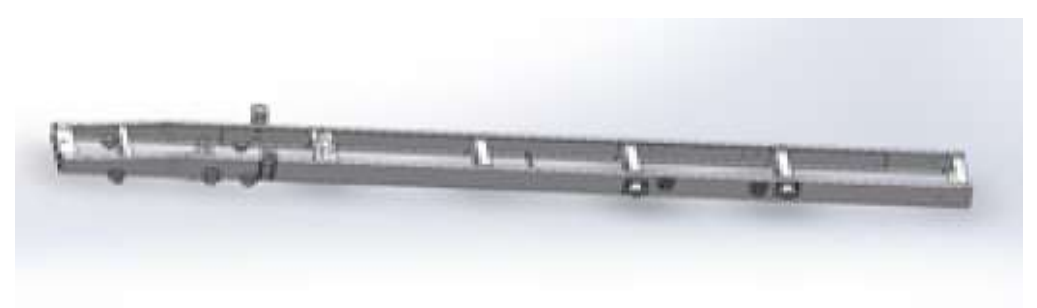

Fig.1: three dimensional model of frame

2.2. Defining material properties: The longitudinal beam of the frame is made of $16 \mathrm{Mn}$, the cross beam, lining plate, reinforcing plate and other parts are made of Q235, and the equivalent spring is made of 60Si2Mn. Its material properties are shown in Table 1.

Table 1: material properties of frame

\begin{tabular}{|c|c|c|c|c|}
\hline $\begin{array}{c}\text { Material } \\
\text { Science }\end{array}$ & Density (g/cm $\left.{ }^{\mathbf{3}}\right)$ & $\begin{array}{c}\text { Elastic } \\
\text { modulus (GPa) }\end{array}$ & $\begin{array}{c}\text { Poisson's } \\
\text { ratio }\end{array}$ & $\begin{array}{c}\text { Yield } \\
\text { limit (MPa) }\end{array}$ \\
\hline $16 \mathrm{Mn}$ & 7.8 & 206 & 0.3 & 350 \\
\hline Q235 & 7.85 & 210 & 0.33 & 235 \\
\hline $60 \mathrm{Si} 2 \mathrm{Mn}$ & 7.85 & 206 & 0.3 & 1180 \\
\hline
\end{tabular}

2.3. Cell type and Meshing: The frame model is imported into ANSYS software. The frame longitudinal beam and cross beam adopt shell element (shell181), solid element (solid187) is selected for solid parts (such as lifting lug), and the leaf spring is equivalent to circular arc plate. The hexahedron based grid control method is used for grid division. The established frame finite element model is shown in Figure 1-2, including 86707 elements and127565nodes ${ }^{[3]}$. 


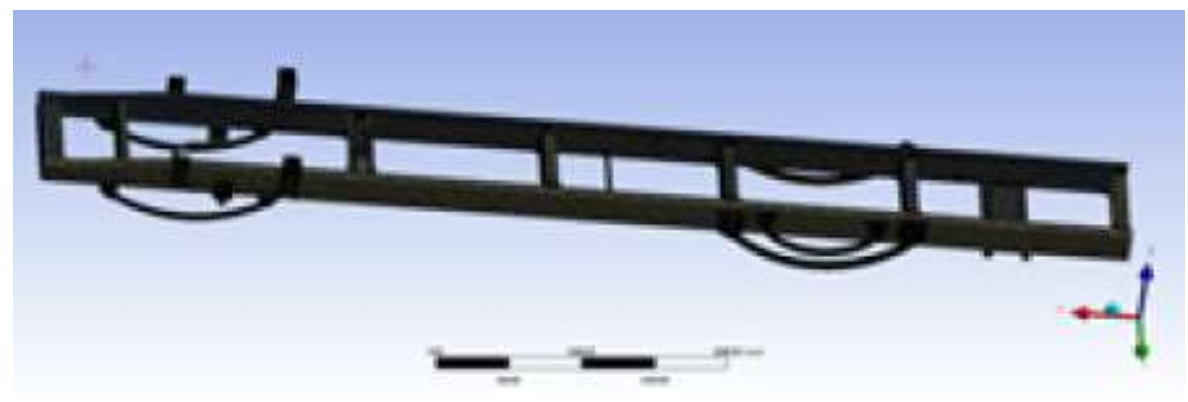

Fig.2: finite element model of frame

2.4. Application of restraint loads: The load of the frame is composed of several parts, mainly including the weight load of the engine, gearbox, oil tank, battery box, cab assembly and the frame itself, as well as the cargo load. The engine, gearbox and other accessories are applied to the corresponding nodes of the frame in the form of concentrated load, the goods and cab assembly are applied to the upper surface of the longitudinal beam in the form of uniform load, and the load generated by the gravity and inertia force of the frame is automatically added to the unit by setting gravity acceleration and external acceleration. In order to accurately analyze the working performance of truck frame under driving conditions, the influence of dynamic load is also considered in this paper, and the dynamic load coefficient is used to evaluate the size of dynamic load ${ }^{[3]}$.During the static analysis of the frame, the deformation of the frame shall meet the requirements, and the maximum stress value shall not be greater than the allowable stress.

When applying constraints to the frame model, the constraints should be controlled within a reasonable range to prevent the application of over constraints. In this paper, the constraints are applied at the symmetrical position in the middle of the lowest end of the equivalent leaf spring, so as to simulate the actual driving situation of the vehicle ${ }^{[4-5]}$.

\section{RESULT AND DESCUSSION}

\subsection{Static analysis}

3.1 Bending condition: The bending condition is to simulate the stress distribution and deformation of the truck traveling in a straight line on a good road when the truck is fully loaded and four wheels touch the ground. The dynamic load coefficient of the frame is set to 2 , and the specific frame boundary conditions are shown in table 2 .

Table 2: boundary conditions under bending conditions

\begin{tabular}{|c|c|c|c|c|}
\hline Position & $\begin{array}{c}\text { Left front } \\
\text { wheel }\end{array}$ & $\begin{array}{c}\text { Right-front } \\
\text { wheel }\end{array}$ & $\begin{array}{c}\text { Left rear } \\
\text { wheel }\end{array}$ & $\begin{array}{c}\text { Right rear } \\
\text { wheel }\end{array}$ \\
\hline Constrained degrees of freedom & X.Y.Z & X.Z & Y.Z & Z \\
\hline
\end{tabular}

The stress nephogram of the frame under full load bending condition is shown in Figure 3. 


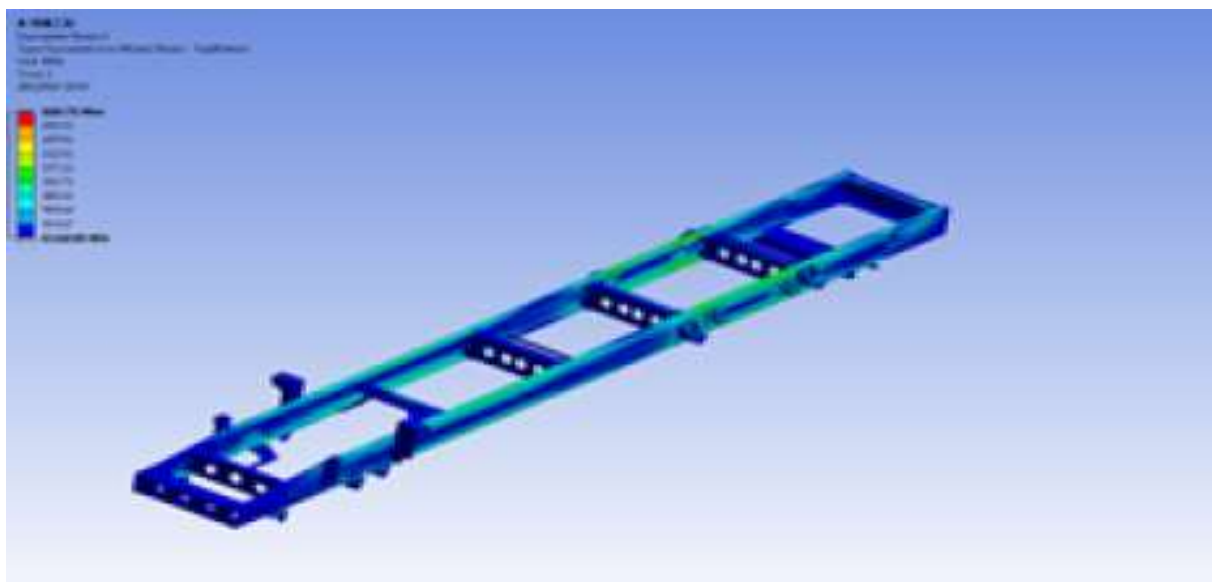

Fig.3: stress nephogram under bending condition

According to the stress nephogram, the stress on the frame is relatively uniform. The maximum stress point is located in the intersection area between the upper and lower wing surfaces of the left and right longitudinal beams and the fifth cross beam. The maximum stress value is about $260 \mathrm{mpa}$, which is less than the allowable stress of $350 \mathrm{Mpa}$, meeting the requirements.

3.2 Torsional condition analysis: Torsional working condition refers to the stress distribution and displacement distribution of the frame when the truck is driving on a rough road and bears asymmetric load. In this paper, the suspension of the right rear wheel is selected for analysis. Under this condition, the vehicle speed is low and can be regarded as a static condition. The dynamic load coefficient is 1 . The load application is the same as that under bending condition. The boundary conditions of the frame under torsion condition are set as shown in table 3.

Table 3: Boundary conditions under torsional conditions

\begin{tabular}{|c|c|c|c|c|}
\hline Position & $\begin{array}{c}\text { Left front } \\
\text { wheel }\end{array}$ & $\begin{array}{c}\text { Right-front } \\
\text { wheel }\end{array}$ & $\begin{array}{c}\text { Left rear } \\
\text { wheel }\end{array}$ & $\begin{array}{c}\text { Right rear } \\
\text { wheel }\end{array}$ \\
\hline Constrained degrees of freedom & $\mathrm{Z}$ & $\mathrm{Z}$ & X.Y.Z & \\
\hline
\end{tabular}

The stress nephogram of the frame under torsional condition is shown in Fig.2-2.

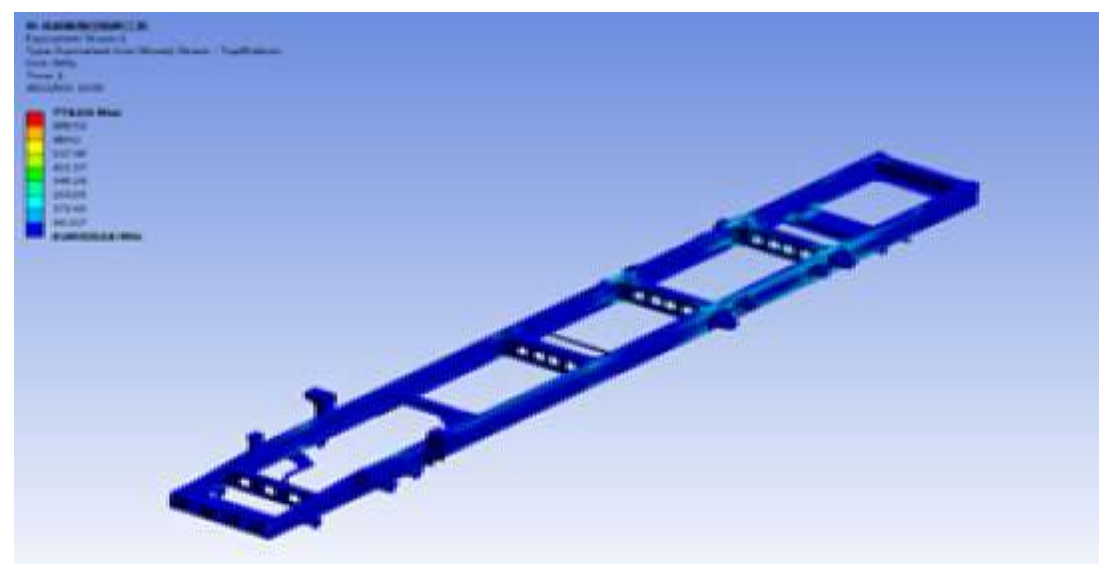

Fig.4: stress nephogram under torsional condition 
It can be seen from the above figure that most of the stress on the frame is within the allowable stress range, but there is stress concentration at the connection between the fourth and fifth cross beams and longitudinal beams of the frame, which will reduce the service life of the frame. It is necessary to add reinforcing plates at corresponding positions to reduce the stress concentration area of the frame and ensure the safety of vehicle use.

\section{CONCLUSION}

Based on the static analysis theory, this paper analyzes the stress distribution of the frame of a heavy truck under bending and torsion conditions by using the ANSYS Workbench software to determine whether the frame meets the strength design requirements. From the above stress nephogram, it can be concluded that the maximum stress area of the frame under bending condition is within the range of strength design requirements, which proves that the frame basically meets the requirements of bending condition; However, the stress concentration under torsional condition exceeds the allowable stress, so it is necessary to make some improvement and simulation analysis. According to the stress analysis under bending and torsion conditions, the following improvement methods are proposed:

1. Increase the wall thickness of the fourth and fifth transverse beams to reduce their deformation.

2. Avoid drilling at the connection between the fourth and fifth cross beams and longitudinal beams to reduce stress concentration.

3. When arranging the load, try to make the load act directly on the cross beam to reduce the frame deformation under torsional conditions.

4. Under the condition of meeting the basic strength requirements, increase the number of holes in the first and second beams to reduce the dead weight of the frame.

\section{REFERENCE}

1. Yu Zhisheng. Automobile theory [M]. Beijing: Machinery Industry Press, 2000.

2. Tan Jijin. Automobile finite element method [M]. Beijing: People's Communications Press, 2005.

3. Ji Zhiyong. Structural design and performance analysis of electric logistics vehicle frame [D]. Taiyuan University of technology, 2019.

4. Chen Zheng, Li Hongxun, Gao Chaowang, et al. Finite element analysis of a transport vehicle frame based on ANSYS Workbench [ J ] . Agricultural equipment and vehicle engineering, 2012, 50 (12): 44-47.

5. Han Yang. Finite element analysis and optimization design of light truck frame [D]. Dalian Jiaotong University, 2019.

\section{* Corresponding Author: SUN Hongyi}

College of Transportation and Vehicle Engineering, Shandong University of

Technology, Zibo 255049, China

Online date of publication: 12.10 .2021 